\title{
Correction to: The Hydrogen Bond, the Halogen Bond and Rotational Spectroscopy: A Personal Retrospective
}

\section{Anthony Legon ${ }^{*}$ (1)}

1 Correction to: J. Indian Inst. Sci.

https://doi.org/10.1007/s41745-

019-00147-3

The symbol $\varpi$ appears erroneously in thirteen places in the text of this article. It should be replaced in each case by the symbol $\pi$.

\section{Publisher's Note}

Springer Nature remains neutral with regard to jurisdictional claims in published maps and institutional affiliations. 